\title{
Prevalence and prognostic implications of psychological distress in patients with gastric cancer
}

\author{
Gun Min Kim², Seung Jun Kim², Su Kyung Song ${ }^{3}$, Hye Ryun Kim, Beo Deul Kang ${ }^{4}$, Sung Hoon Noh, \\ Hyun Cheol Chung ${ }^{1}$, Kyung Ran Kim ${ }^{6^{*}}$ and Sun Young Rha ${ }^{1 *}$
}

\begin{abstract}
Background: The aim of this study was to investigate the prevalence and prognostic significance of psychological distress in gastric cancer patients.

Methods: The study population included 229 gastric cancer patients visiting Yonsei Cancer Center between November 2009 and March 2011. The distress was measured by available tools including the Modified Distress Thermometer (MDT), Hospital Anxiety and Depression Scale (HADS), and Center for Epidemiologic Studies-Depression Scale (CES-D). Patients with psychological distress were defined as those who scored above the cut-off values in both the MDT and either one of the HADS or CES-D.

Results: The median age of patients was 56 (range, 20 to 86) and 97 (42.4\%) patients were with stage IV disease status at enrollment. The overall prevalence of psychological distress was 33.6\% (95\% Cl: 27.5-39.8\%) in 229 gastric cancer patients. In multiple logistic regression analysis, lower education level (odds ratio [OR] 2.39; 95\% confidence interval [CI] $1.11-5.17, P=0.026)$ and higher disease stage (OR 2.72; $95 \% \mathrm{Cl} 1.47-5.03, P=0.001)$ were associated with psychological distress. In stage I-III disease, patients with psychological distress had worse disease-free survival (DFS) (5-year DFS rate: $60 \%$ vs $76 \%, P=0.49$ ) compared with those without psychological distress. In stage IV disease $(n=97)$, patients with psychological distress showed poorer overall survival than those without psychological distress (median OS (Overall Survival): 12.2 vs. 13.8 months, $P=0.019$ ).
\end{abstract}

Conclusion: Psychological distress is common in patients with all stages of gastric cancer and is associated with worse outcomes.

Keywords: Psychological distress, Gastric cancer, Prognosis, Survival

\section{Background}

Cancer diagnosis and treatment is a significantly stressful event that generates psychological distress in a large number of cancer patients. Psychological distress is generally defined as a state of emotional suffering characterized by symptoms of depression and anxiety [1]. Approximately $20-40 \%$ of cancer patients show a significant level of psychological distress [2, 3]. Distress can

\footnotetext{
*Correspondence: drgreat@yuhs.ac; rha7655@yuhs.ac

${ }^{6}$ Department of Psychiatry, Yonsei University College of Medicine, Seoul, South Korea

${ }^{1}$ Division of Medical Oncology, Department of Internal Medicine, Yonsei University College of Medicine, 50 Yonsei-ro, Seodaemun-gu, Seoul 120-752, South Korea

Full list of author information is available at the end of the article
}

exert a negative impact on their treatment adherence, quality of life (QOL), pain, and even on survival [4-8]. Recently, in most solid cancers including gastric cancer, the multidisciplinary approach is becoming more important for the decision of cancer treatment strategy and psychosocial support is one of the essential parts of the multidisciplinary approach $[9,10]$.

Gastric cancer is the second leading cause of cancer deaths in the world [11]. Most patients with gastric cancer have advanced to an incurable stage at the time of diagnosis, which induces tremendous psychological stress. Even if the patient is diagnosed with early-stage gastric cancer, they suffer from not only the diagnosis of cancer but also surgery itself [12]. Therefore, the importance of psychological 
distress in gastric cancer patients for the decision of treatment will continue to grow.

Few studies have reported on the prevalence or the nature of psychological distress in gastric cancer patients. Tavoli et al. reported that overall $47.2 \%$ and $57 \%$ of patients with gastrointestinal cancer scored high on both anxiety and depression respectively [13]. We previously reported the prevalence and associated factors of psychological distress in all types of cancer patients and found that $28.3 \%$ of gastric cancer patients had psychological distress [14]. Further, there is no report of the survival impact of psychological distress in gastric cancer patients.

The aim of this study was to evaluate the prevalence and prognostic impact of psychological distress in gastric cancer patients.

\section{Methods}

\section{Study population}

Patients were eligible for study participation if they met the following criteria: 1) histologically confirmed gastric adenocarcinoma; 2) age of $>20$ years; 3) Eastern Cooperative Oncology Group (ECOG) performance status $0-3$; 4) the ability to read and understand the questionnaire; 5) the ability to communicate in written and spoken language; and 6) willing and able to provide written informed consent.

Patients with operable gastric cancer underwent surgery and then received adjuvant chemotherapy according to the final pathologic stage. Stage IV gastric cancer patients received a standard treatment of palliative systemic chemotherapy with or without palliative gastrectomy.

Patients with gastric cancer visiting Yonsei Cancer Center, Severance Hospital in Seoul, Korea between November 2009 and March 2011 were included. Patients were enrolled at the first visit to the medical oncology department. During the study period, 298 gastric cancer patients agreed to complete questionnaires for screening distress. Among them, 249 (83.5\%) patients completed all questionnaires. We excluded 20 patients in the final analysis due to several reasons (such as neoadjuvant chemotherapy, follow-up loss, treatment refusal, etc.) Finally, we analyzed the data of 229 gastric cancer patients (Fig. 1).

\section{Study procedure}

An Oncology Certified Nurse (OCN) explained the purpose and procedure of the distress screening program to gastric cancer patients in the oncology outpatient clinic. Patients who signed informed consent forms completed questionnaires containing the Modified Distress Thermometer (MDT), Hospital Anxiety and Depression Scale (HADS), and Center for Epidemiologic Studies-Depression Scale (CES-D), and questions about socio-demographic and clinical status. Cancer-related information including cancer stage, disease-free survival,

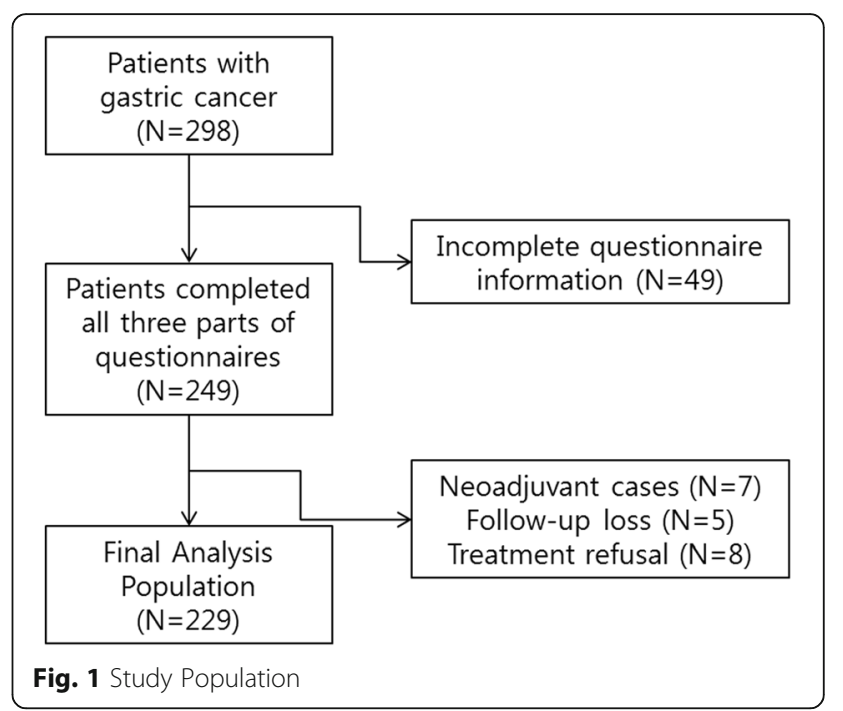

overall survival, and adjuvant chemotherapy were collected in electronic medical records. The patients who were identified as harboring psychological distress were referred to a psychiatrist for further evaluation and treatment for psychological distress by a medical oncologist. An independent psychiatric doctor reviewed the data without any clinical information and informed the oncologist about the status of psychological distress.

\section{Measure of psychological distress}

The following three self-administered questionnaires were used to evaluate the psychological distress of enrolled patients.

The MDT is an easily used screening tool to measure the severity of psychological symptoms including anxiety, insomnia, and depression, and the degree of functional impairment due to these symptoms. It contains three subscales: MDT-anxiety, MDT-insomnia, and MDT-depression. Patients are required to circle the number that corresponds to their severity of distress and the degree of functional impairment on an 11-point visual analogue scale ranging from 0 to 10 by referring to the previous week. More than 4 points in both the severity and impairment scales in each distress symptom indicates that it is necessary to refer to a psychiatrist [15].

The HADS is widely used to measure anxiety and depression in patients with medical illness. It is considered as an effective screening tool to evaluate psychological distress in cancer patients [16, 17]. It consists of two subscales (HADS-A and HADS-D) that evaluate anxiety and depression, respectively. We used the Koreanvalidated version of the HADS for this study. Scores for each subscale range from 0 to 21 and a cut-off score of 8 was used, which had been previously reported to show good sensitivity and specificity (89.2 and $82.5 \%$, respectively) in a Korean population [18]. Patients who scored 
above the cut-off score in either the HADS-A or HADSD scale were defined as one with psychological distress based on the HADS.

The CES-D is a 20-item tool used to evaluate depressive symptoms in the general population. The Korean version of the CES-D was used in this study and we defined a CES-D score of 21 as the cut-off score, which was reported to be the threshold for the purpose of estimating the prevalence of depressive symptoms in Korean patients [19].

In this study, patients with psychological distress were defined as those who scored above the cut-off value in both MDT scales and either one of the HADS or CES-D scales.

\section{Statistical analysis}

In order to compare psychological distress with regard to socio-demographic and clinical characteristics, chisquare tests were conducted for categorical and nominal variables, and independent samples t-test and analyses of variance (ANOVA) were performed for continuous variables. Standard univariate descriptive statistics were used to calculate the prevalence of distress. Logistic regression analysis was conducted to evaluate the factors that show the strongest association with psychological distress. Univariate and multivariate Cox proportional hazards models were used to determine the effect of independent predictors on survival times. Disease-free survival (DFS) was defined as the time from the date of surgery to the disease recurrence or death from any other causes. All statistical analysis was conducted using SPSS, software version 23.0 (SPSS Inc.).

\section{Results}

\section{Patient characteristics}

Table 1 shows the socio-demographic and clinical data of the evaluable 229 patients. The median age of the patients was 56 years (range: 20-86), and 167/229 (73\%) were male. Most patients were married (196/229 [85.6\%]), and more than half of the participants were high school educated or higher (178/229 [77.8\%]) and unemployed (121/229 [52.8\%]). Patients with metastatic or recurrent disease (stage IV) at enrollment were $42.4 \%$. Most of the patients were non-smokers (79.9\%) and physically active (ECOG 0 or 1: 94.7\%). Among stage I-III disease patients $(n=132), 83$ patients received adjuvant chemotherapy after surgery. The proportion of patients who received adjuvant chemotherapy in stage I, II, and III was $2.9 \%, 81.8 \%$, and $83.1 \%$, respectively. The most commonly used chemotherapy regimen was platinum-based doublet, for $67.5 \%$ with an adjuvant aim and $73.1 \%$ with a palliative aim. Of 97 patients with recurrent or metastatic disease at enrollment, more than half of the patients (53.6\%) had peritoneal metastases at
Table 1 Baseline characteristics

\begin{tabular}{|c|c|c|}
\hline & $N=229$ & $\%$ \\
\hline \multicolumn{3}{|l|}{ Age } \\
\hline Median & 56 & \\
\hline Range & $20-86$ & \\
\hline \multicolumn{3}{|l|}{ Gender } \\
\hline Male & 167 & 72.9 \\
\hline Female & 62 & 27.1 \\
\hline \multicolumn{3}{|l|}{ ECOG Performance } \\
\hline 0 & 121 & 52.8 \\
\hline 1 & 96 & 41.9 \\
\hline $2-3$ & 12 & 5.2 \\
\hline \multicolumn{3}{|l|}{ Smoking } \\
\hline Smoker & 46 & 20.1 \\
\hline Non-Smoker & 183 & 79.9 \\
\hline \multicolumn{3}{|l|}{ Marital status } \\
\hline Married & 196 & 85.6 \\
\hline Single & 17 & 7.4 \\
\hline Widowed & 12 & 5.2 \\
\hline Divorced & 4 & 1.7 \\
\hline \multicolumn{3}{|l|}{ Educational level } \\
\hline Elementary school & 24 & 10.5 \\
\hline Middle school & 27 & 11.8 \\
\hline High school & 86 & 37.6 \\
\hline Undergraduate & 74 & 32.3 \\
\hline Graduate school & 18 & 7.9 \\
\hline \multicolumn{3}{|l|}{ Employment status } \\
\hline Full-time job & 82 & 35.8 \\
\hline Part-time job & 26 & 11.4 \\
\hline Unemployed & 82 & 35.8 \\
\hline Housewife/Student & 39 & 17 \\
\hline \multicolumn{3}{|l|}{ Histology } \\
\hline Tubular adenocarcinoma & 161 & 70.3 \\
\hline Signet ring cell carcinoma & 58 & 25.3 \\
\hline Mucinous carcinoma & 5 & 2.2 \\
\hline Others & 5 & 2.2 \\
\hline \multicolumn{3}{|l|}{ Adjuvant chemotherapy } \\
\hline Platinum-based doublet (SP or FP) & $56 / 83$ & 67.5 \\
\hline TS-1 monotherapy & $22 / 83$ & 26.5 \\
\hline Others & $5 / 83$ & 6 \\
\hline \multicolumn{3}{|l|}{ Initial metastasis site } \\
\hline Peritoneum & $52 / 97$ & 53.6 \\
\hline Distant LN & $41 / 97$ & 42.3 \\
\hline Liver & 28/97 & 28.9 \\
\hline Bone & $12 / 97$ & 12.4 \\
\hline Lung & 9/97 & 9.3 \\
\hline
\end{tabular}


Table 1 Baseline characteristics (Continued)

\begin{tabular}{lll}
\hline Brain & $2 / 97$ & 2.1 \\
Others & $19 / 97$ & 19.6 \\
Palliative chemotherapy & & \\
No & $15 / 97$ & 15.5 \\
Yes & $82 / 97$ & 84.5 \\
Palliative chemotherapy regimen & & \\
Platinum-based doublet (SP or FP) & $60 / 82$ & 73.2 \\
Taxane-based regimen & $12 / 82$ & 14.6 \\
Triplet (DCF) & $2 / 82$ & 2.4 \\
Others & $8 / 82$ & 9.7 \\
AJCC stage at enrollment & & \\
1 & 34 & 14.8 \\
2 & 33 & 14.4 \\
3 & 65 & 28.4 \\
4 & 97 & 42.4 \\
\hline
\end{tabular}

diagnosis and $84.5 \%$ received palliative chemotherapy in the first-line setting. Fifteen patients with recurrent or metastatic disease underwent palliative surgery for several purposes such as clinical trials $(n=4)$, good responder to palliative chemotherapy $(n=8)$, and palliation of symptoms $(n=3)$.

\section{Prevalence of psychological distress in gastric cancer patients}

The results of distress screening through the questionnaires are shown in Table 2. Among the 229 patients, 77 (33.6\%) were identified as patients with psychological distress. Using the MDT, 50 patients reported insomnia (21.8\%), 69 anxiety (30.1\%), or 68 depression (29.7\%). The number of patients who scored above the cutoff value in HADS-A, HADS-D, and CES-D was 62 (27.1\%), 92 (40.2\%), and 76 (33.2\%), respectively. Concordance between the parameters are displayed in Fig. 2. Among
77 patients with psychological distress, $61 \%$ had positive results for all three methods. Patients who are in the shaded area in Fig. 2c were defined as patients with psychological distress. The prevalence of psychiatric illness diagnosed by the psychiatrist is shown in Additional file 1: Table S1.

\section{Risk factors of psychological distress}

Table 3 describes the comparison of socio-demographic and clinical factors between patients with and without psychological distress. Patients with psychological distress were significantly higher in females $(P=0.024)$, the unemployed $(P=0.02)$, those with lower educational background $(P=0.021)$, and those at an advanced stage $(P=0.008)$. The logistic regression analysis showed that education, disease stage, and smoking status maintained a statistically significant association with psychological distress (Additional file 1: Table S2). The patients with low education levels were 2.39 times (95\% CI, 1.11-5.17, $P=0.026)$ more likely to have psychological distress than those with high education levels. The patients with stage IV incurable disease stage were 2.72 times (95\% CI, 1.47-5.03, $P=0.001)$ more likely to have psychological distress than those with a curable disease stage.

\section{Survival analysis}

The median follow-up duration of the entire cohort was 42.5 months. We analyzed survival data divided into two subsets (curable disease, stage I-III vs. incurable disease, stage IV). DFS by TNM (Tumor/Node/Metastasis) substage are shown in Additional file 1: Figure S1. In stage I-III disease, patients who have psychological distress had worse disease-free survival (5-year DFS rate: $60 \%$ vs $76 \%, P=0.49$, Fig. 3a). In stage IV disease, patients with psychological distress had worse OS than those without psychological distress (median OS: 12.2 vs. 13.8 months, $P=0.019$, Fig. 3b).

Table 2 Prevalence of psychological distress by disease stage

\begin{tabular}{|c|c|c|c|c|c|c|c|}
\hline & \multicolumn{2}{|c|}{ All Patients } & \multicolumn{2}{|l|}{ Stage |-||| } & \multicolumn{2}{|c|}{ Stage IV } & \multirow[b]{2}{*}{$P$-value } \\
\hline & $N=229$ & $\%$ & $N=132$ & $\%$ & $N=97$ & $\%$ & \\
\hline MDT & 93 & 40.6 & 46 & 34.8 & 47 & 48.5 & 0.038 \\
\hline Insomnia & 50 & 21.8 & 28 & 21.2 & 22 & 22.7 & 0.79 \\
\hline Anxiety & 69 & 30.1 & 30 & 22.7 & 39 & 40.2 & 0.004 \\
\hline Depression & 68 & 29.7 & 31 & 23.5 & 37 & 38.1 & 0.016 \\
\hline HADS & 106 & 46.3 & 52 & 39.4 & 54 & 55.7 & 0.015 \\
\hline HADS-A & 62 & 27.1 & 29 & 22 & 33 & 34 & 0.043 \\
\hline HADS-D & 92 & 40.2 & 45 & 34.1 & 47 & 48.5 & 0.028 \\
\hline CES-D & 76 & 33.2 & 38 & 28.8 & 38 & 39.2 & 0.099 \\
\hline Psychological distress & 77 & 33.6 & 35 & 26.5 & 42 & 43.3 & 0.008 \\
\hline
\end{tabular}

MDT Modified Distress Thermometer, HADS Hospital Anxiety and Depression Scale, CES-D Center for Epidemiologic Studies-Depression Scale 


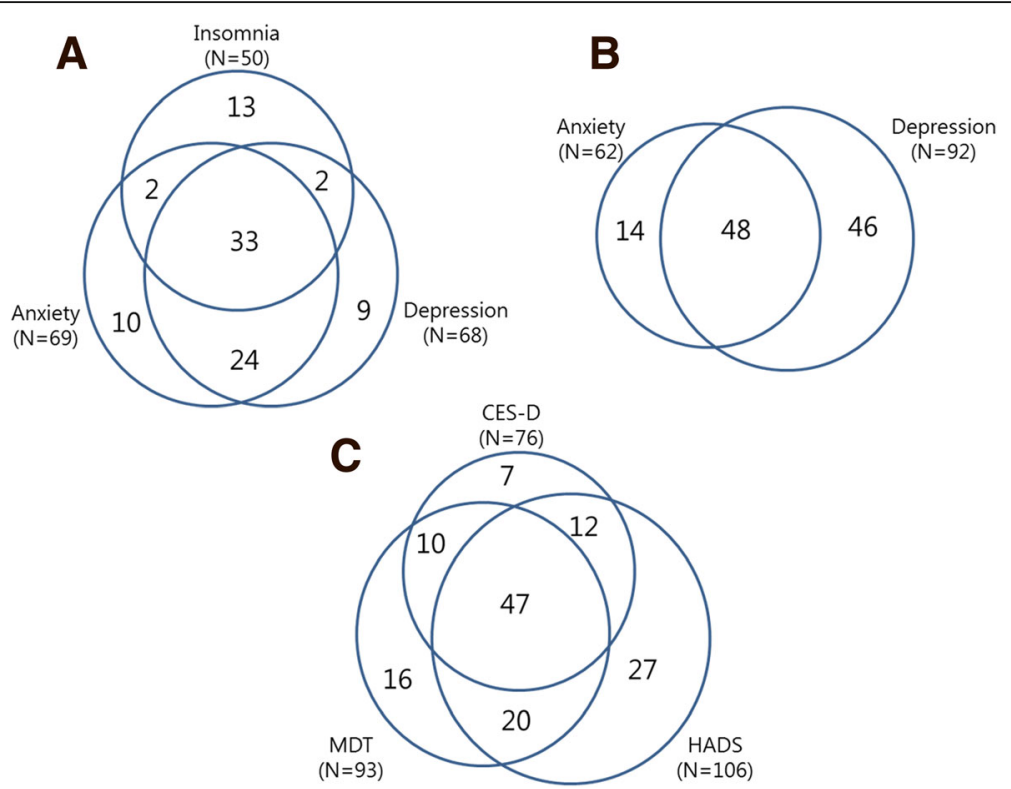

Fig. 2 Concordance rate between distress measure parameters (a) MDT (b) HADS (c). All three distress parameters; Shaded area are the patient who was defined as psychological distress in this study

The Cox multivariate analysis model including age, gender, ECOG, adjuvant chemotherapy, marriage, education, employment, and psychological distress in stage III disease showed that adjuvant chemotherapy (Hazzard ratio [HR] 7.23, 95\% CI 2.27-22.95, $P<0.001)$ and psychological distress (HR 2.47, 95\% CI 1.07-5.68, $P=0.034)$ were associated with shorter disease free survival (Table 4).

\section{Discussion}

Psychological support is an important part of the multidisciplinary approach, but there is no study that specifically evaluated the psychological distress in gastric cancer, which is the most common cancer in Korea. To our knowledge, this is the first study to explore the prevalence and prognostic impact of psychological distress among a large number of patients with gastric cancer. In our study cohort of gastric cancer patients, significant psychological distress was identified in $33.6 \%$ of patients. In addition, we found that psychological distress has a poor prognostic impact for gastric cancer patients.

The presence of psychological distress is a risk factor for treatment noncompliance. A meta-analysis showed that noncompliance was greater in patients with depression compared to non-depressed patients [20]. Therefore, it is important to identify the patients who may be vulnerable to psychological distress to improve treatment adherence. We found that the patients with advanced disease, low levels of education, and who were female were found to be significantly vulnerable to psychological distress. These findings are comparable to previous studies [21-24]. Several studies reported a higher prevalence of psychological distress in patients with lower education. Lower coping skills seem to contribute to the higher rate of psychological distress in those with little education [24].

Kuchler et al. reported that patients with gastrointestinal cancer including stomach, pancreatic, liver, or colorectal cancer who received a formal program of psychotherapeutic support during their hospital stay showed a better survival than those who did not [25]. In this study population, there were few recurrence cases in stage I or II disease; therefore, we performed a multivariate survival analysis in stage III disease. Although not statistically significant, patients who had psychological distress were less likely to receive adjuvant chemotherapy than those who did not. Treatment non-compliance related with adjuvant therapy could be one of the reasons for the poor survival in patients with psychological distress.

There are many screening tools with variable formats and lengths for evaluating psychological distress. However, it is not clear which screening method is appropriate for cancer patients. The Distress Thermometer (DT) is widely used due to its simplicity, but it is generally poor accuracy was pointed as a limitation [26]. To compensate this weakness, we added two other scales for the evaluation of psychological distress. In this study, we also have to consider the balance between minimizing the burden on patients and maximizing validity of data. We selected three short-length screening tools-MDT, HADS, and CES-D-that were validated by several studies [27]. We also previously reported the sensitivity and 
Table 3 Comparison of socio-demographic characteristics between the patients with psychological distress and those without psychological distress

\begin{tabular}{|c|c|c|c|c|c|}
\hline & \multicolumn{2}{|c|}{ Patients without psychological distress } & \multicolumn{2}{|c|}{ Patients with psychological distress } & \multirow[b]{2}{*}{$P$-value } \\
\hline & $N=152$ & $\%$ & $N=77$ & $\%$ & \\
\hline Age & & & & & 0.289 \\
\hline Mean (SD) & & $57(13)$ & & $55(12.7)$ & \\
\hline Gender & & & & & 0.024 \\
\hline Male & 118 & 77.6 & 49 & 63.6 & \\
\hline Female & 34 & 22.4 & 28 & 36.4 & \\
\hline ECOG Performance & & & & & 0.055 \\
\hline 0 & 82 & 53.9 & 39 & 50.6 & \\
\hline 1 & 66 & 43.4 & 30 & 39 & \\
\hline $2-3$ & 4 & 2.6 & 8 & 10.4 & \\
\hline Smoking & & & & & 0.056 \\
\hline Smoker & 116 & 76.3 & 67 & 87 & \\
\hline Non-Smoker & 36 & 23.7 & 10 & 13 & \\
\hline Marital status & & & & & 0.247 \\
\hline Married & 133 & 87.5 & 63 & 81.8 & \\
\hline Unmarried & 19 & 12.5 & 14 & 18.2 & \\
\hline Educational status & & & & & 0.021 \\
\hline$\leq$ Middle school & 27 & 17.8 & 24 & 31.2 & \\
\hline$\geq$ High school & 125 & 82.2 & 53 & 68.8 & \\
\hline Employment status & & & & & 0.02 \\
\hline Employed & 80 & 52.6 & 28 & 36.4 & \\
\hline Unemployed & 72 & 47.4 & 9 & 63.6 & \\
\hline Disease stage at enrollment & & & & & 0.008 \\
\hline $1-3$ & 97 & 63.8 & 35 & 45.5 & \\
\hline 4 & 55 & 36.2 & 42 & 54.5 & \\
\hline Disease status at enrollment & & & & & 0.072 \\
\hline Post-op status & 64 & 42.1 & 23 & 29.9 & \\
\hline Pre-op or metastatic & 88 & 57.9 & 54 & 70.1 & \\
\hline
\end{tabular}

SD Standard Deviation, ECOG Eastern Cooperative Oncology Group
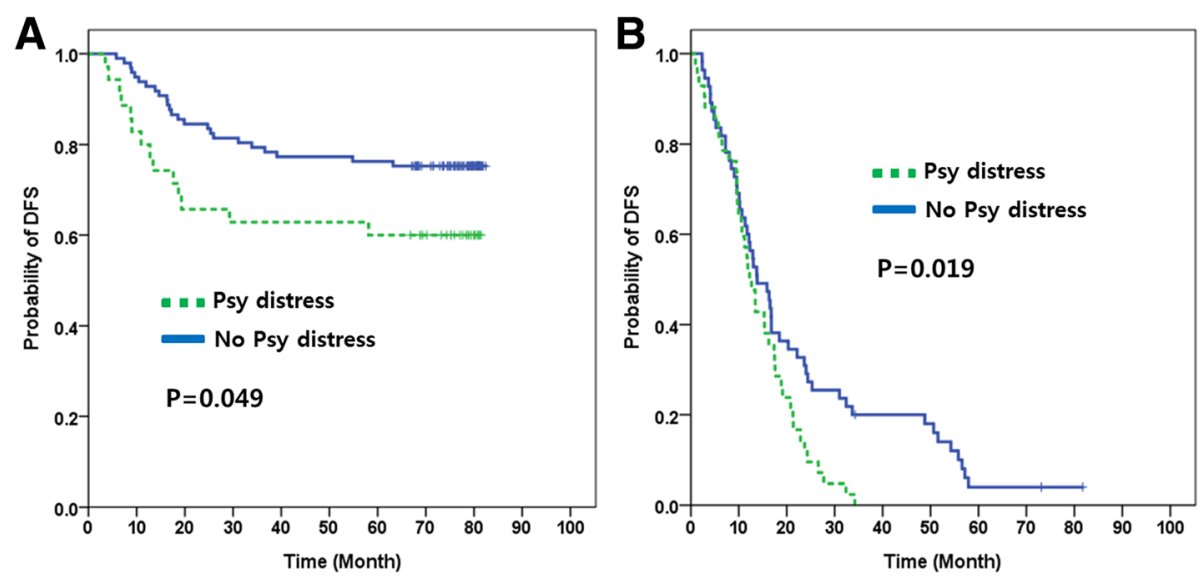

Fig. 3 (a) DFS in Stage I-III disease and (b) OS in Stage IV disease by psychological distress 
Table 4 Disease-free survival multivariate analysis in Stage III Disease

\begin{tabular}{|c|c|c|c|c|}
\hline \multirow[b]{2}{*}{ Factor } & \multirow[b]{2}{*}{$\mathrm{N}$} & \multicolumn{3}{|c|}{ Multivariate analysis } \\
\hline & & Hazzard ratio & $95 \% \mathrm{Cl}$ & $p$-value \\
\hline \multicolumn{5}{|l|}{ Gender } \\
\hline Male & 39 & 1 & & \\
\hline Female & 26 & 2.05 & $0.85-4.91$ & 0.108 \\
\hline \multicolumn{5}{|l|}{ Age } \\
\hline$<65$ & 32 & 1 & & \\
\hline$\geq 65$ & 33 & 1.34 & $0.47-3.79$ & 0.585 \\
\hline \multicolumn{5}{|l|}{ ECOG Performance } \\
\hline 0 & 28 & 1 & & \\
\hline$>1$ & 37 & 1.27 & $0.54-2.97$ & 0.584 \\
\hline & \multicolumn{4}{|c|}{ Adjuvant chemotherapy } \\
\hline Yes & 54 & 1 & & \\
\hline No & 11 & 7.23 & $2.27-22.95$ & $<0.001$ \\
\hline \multicolumn{5}{|l|}{ Psychological distress } \\
\hline No & 45 & 1 & & \\
\hline Yes & 20 & 2.47 & $1.07-5.68$ & 0.034 \\
\hline \multicolumn{5}{|l|}{ Marital status } \\
\hline Married & 54 & 1 & & \\
\hline Unmarried & 11 & 1.562 & $0.53-4.59$ & 0.417 \\
\hline \multicolumn{5}{|l|}{ Educational status } \\
\hline$\leq$ Middle school & 18 & 1 & & \\
\hline$\geq$ High school & 47 & 0.49 & $0.21-1.39$ & 0.154 \\
\hline \multicolumn{5}{|l|}{ Employment status } \\
\hline Employed & 29 & 1 & & \\
\hline Unemployed & 36 & 1.98 & $0.72-5.45$ & 0.187 \\
\hline
\end{tabular}

specificity of these tools in Korean cancer patients [14]. However, considering that 49 (16.5\%) patients did not answer the questions completely, filling out all three questionnaires was clearly some burden to cancer patients. Further studies are warranted to develop efficient tools reflecting the distinct characteristics of Korean culture.

There are several limitations in our study. First, the timing of surveillance was not consistent in all populations. Some patients filled out the questionnaires after hearing the prognosis of their disease, and others did when not knowing their prognosis or treatment plan. Second, we could not follow the development of psychological distress over the trajectory of cancer because of our cross-sectional design. Third, these data were obtained by self-report, and it is possible that patients may have under- or overestimated their status. Fourth, systemic chemotherapy for metastatic gastric cancer was not standardized.

Despite these limitations, this study has important strengths. First, our study demonstrates that approximately one-third of gastric cancer patients have significant psychological distress, especially in low-educated patients with advanced stage disease. The patients with psychological distress showed poor survival outcomes that may be related with treatment non-compliance.

\section{Conclusions}

Psychological distress is common in patients with all stages of gastric cancer and is associated with worse outcomes. From these results, we conclude that we need to pay attention to the psychological status of gastric cancer patients. Ultimately, further research is needed to investigate whether psychotherapeutic interventions would decrease the distress and improve survival outcomes in gastric cancer patients.

\section{Additional file}

Additional file 1: Supplementary figure and tables. Disease free survival differences by TNM sub-stage, psychiatric illness by age group. (DOC $109 \mathrm{~kb}$ )

\section{Abbreviations}

ANOVA: Analyses of variance; CES-D: Center for Epidemiologic Studies-Depression Scale; Cl: Confidence interval; DFS: Disease-free survival; DT: Distress Thermometer; ECOG: Eastern Cooperative Oncology Group; HADS: Hospital Anxiety and Depression Scale; HR: Hazzard ratio; MDT: Modified Distress Thermometer OCN: Oncology Certified Nurse; OR: Odds ratio; OS: Overall Survival; QOL: Quality of life; TNM: Tumor/Node/Metastasis

Acknowledgements

None.

\section{Funding}

This research was supported by the Public welfare \& Safety research program through the National Research Foundation of Korea (NRF) funded by the Ministry of Education, Science and Technology (2010-0020841). The role of funding was the study design and data collection.

Availability of data and materials

The datasets used and/or analyzed during the current study are available from the corresponding author on request.

\section{Authors' contributions}

SYR and KRK designed the study concept. SKS collected the questionnaire results. GMK and SJK analyzed and interpreted the patient data. HRK, BDK, SHN, and HCC contributed to patient enrollment. GMK was a major contributor in writing the manuscript. All authors read and approved the final manuscript.

\section{Competing interests}

The authors declare that they have no competing interests.

Consent for publication

Not applicable.

Ethics approval and consent to participate

Institutional Review Board (IRB) approval was obtained at Severance Hospital. (4-2009-0312). Written informed consent was obtained from the study subjects.

\section{Publisher's Note}

Springer Nature remains neutral with regard to jurisdictional claims in published maps and institutional affiliations. 


\section{Author details}

'Division of Medical Oncology, Department of Internal Medicine, Yonsel University College of Medicine, 50 Yonsei-ro, Seodaemun-gu, Seoul 120-752, South Korea. ${ }^{2}$ Department of Psychiatry, Konyang University College of Medicine, Daejeon, South Korea. ${ }^{3}$ Outpatient Clinic, Department of Medical Oncology, Severance Hospital, Seoul, South Korea. ${ }^{4}$ Division of Hematology and Medical Oncology, Department of Internal Medicine, Seoul National University Bundang Hospital, Seongnam, South Korea. ${ }^{5}$ Department of Surgery, Yonsei University College of Medicine, Seoul, South Korea. ${ }^{6}$ Department of Psychiatry, Yonsei University College of Medicine, Seoul, South Korea.

Received: 20 December 2016 Accepted: 4 April 2017 Published online: 20 April 2017

\section{References}

1. Mirowsky J, Ross CE. Measurement for a human science. J Health Soc Behav. 2002:43(2):152-70

2. Derogatis LR, Morrow GR, Fetting J, Penman D, Piasetsky S, Schmale AM, Henrichs M, Carnicke Jr CL. The prevalence of psychiatric disorders among cancer patients. JAMA. 1983;249(6):751-7.

3. Zabora J, BrintzenhofeSzoc K, Curbow B, Hooker C, Piantadosi S. The prevalence of psychological distress by cancer site. Psychooncology. 2001;10(1):19-28

4. Spiegel D, Sands S, Koopman C. Pain and depression in patients with cancer. Cancer. 1994:74(9):2570-8.

5. Colleoni M, Mandala M, Peruzzotti G, Robertson C, Bredart A, Goldhirsch A Depression and degree of acceptance of adjuvant cytotoxic drugs. Lancet. 2000;356(9238):1326-7.

6. Skarstein J, Aass N, Fossa SD, Skovlund E, Dahl AA. Anxiety and depression in cancer patients: relation between the hospital anxiety and depression scale and the European Organization for Research and Treatment of cancer Core quality of life questionnaire. J Psychosom Res. 2000:49(1):27-34.

7. Prieto JM, Atala J, Blanch J, Carreras E, Rovira M, Cirera E, Espinal A, Gasto C. Role of depression as a predictor of mortality among cancer patients after stem-cell transplantation. J Clin Oncol. 2005;23(25):6063-71.

8. Chida Y, Hamer M, Wardle J, Steptoe A. Do stress-related psychosocial factors contribute to cancer incidence and survival? Nat Clin Pract Oncol. 2008:5(8):466-75.

9. Goodwin PJ, Leszcz M, Ennis M, Koopmans J, Vincent L, Guther H, Drysdale E, Hundleby M, Chochinov HM, Navarro M, et al. The effect of group psychosocial support on survival in metastatic breast cancer. N Engl J Med. 2001;345(24):1719-26.

10. Carlsen $\mathrm{K}$, Jensen $A B$, Jacobsen $E$, Krasnik M, Johansen C. Psychosocial aspects of lung cancer. Lung Cancer. 2005;47(3):293-300.

11. Kelley JR, Duggan JM. Gastric cancer epidemiology and risk factors. J Clin Epidemiol. 2003;56(1):1-9.

12. Matsushita T, Matsushima E, Maruyama M. Anxiety and depression of patients with digestive cancer. Psychiatry Clin Neurosci. 2005;59(5):576-83.

13. Tavoli A, Mohagheghi MA, Montazeri A, Roshan R, Tavoli Z, Omidvari S. Anxiety and depression in patients with gastrointestinal cancer: does knowledge of cancer diagnosis matter? BMC Gastroenterol. 2007;7:28.

14. Kim SJ, Rha SY, Song SK, Namkoong K, Chung HC, Yoon SH, Kim GM, Kim KR. Prevalence and associated factors of psychological distress among Korean cancer patients. Gen Hosp Psychiatry. 2011:33(3):246-52.

15. National Cancer Center, Recommendations for distress Management in Cancer Patients, 2008; Available from: http://www.cancer.go.kr/mbs/cancer/ subview.jsp?id=cancer_030101010400.

16. Moorey S, Greer S, Watson M, Gorman C, Rowden L, Tunmore R, Robertson $B$, Bliss J. The factor structure and factor stability of the hospital anxiety and depression scale in patients with cancer. Br J Psychiatry. 1991;158:255-9.

17. Ibbotson T, Maguire P, Selby P, Priestman T, Wallace L. Screening for anxiety and depression in cancer patients: the effects of disease and treatment. Eur J Cancer. 1994;30A(1):37-40.

18. Oh SM, Min KJ, Park DB. A study on the standardization of the hospital anxiety and depression scale for Koreans - a comparison of normal, depressed and anxious groups. J Korean Neuropsychiatr Assoc. 1999;38:289-96.

19. Cho MJ, Kim KH. The diagnostic validity of the CES-D (Korean version) in the assessment of DSM-III-R major depression. J Korean Neuropsychiatr Assoc. 1993:32:381-99.
20. DiMatteo MR, Lepper HS, Croghan TW. Depression is a risk factor for noncompliance with medical treatment: meta-analysis of the effects of anxiety and depression on patient adherence. Arch Intern Med. 2000;160(14):2101-7.

21. Shim EJ, Shin YW, Jeon HJ, Hahm BJ. Distress and its correlates in Korean cancer patients: pilot use of the distress thermometer and the problem list. Psychooncology. 2008;17(6):548-55.

22. Graves KD, Arnold SM, Love CL, Kirsh KL, Moore PG, Passik SD. Distress screening in a multidisciplinary lung cancer clinic: prevalence and predictors of clinically significant distress. Lung Cancer. 2007;55(2):215-24.

23. Jacobsen PB, Donovan KA, Trask PC, Fleishman SB, Zabora J, Baker F, Holland JC. Screening for psychologic distress in ambulatory cancer patients. Cancer. 2005;103(7):1494-502.

24. Dalgard OS, Mykletun A, Rognerud M, Johansen R, Zahl PH. Education, sense of mastery and mental health: results from a nation wide health monitoring study in Norway. BMC Psychiatry. 2007;7:20

25. Kuchler T, Bestmann B, Rappat S, Henne-Bruns D, Wood-Dauphinee S. Impact of psychotherapeutic support for patients with gastrointestinal cancer undergoing surgery: 10-year survival results of a randomized trial. J Clin Oncol. 2007:25(19):2702-8.

26. Mitchell AJ. Pooled results from 38 analyses of the accuracy of distress thermometer and other ultra-short methods of detecting cancer-related mood disorders. J Clin Oncol. 2007;25(29):4670-81.

27. Vodermaier A, Linden W, Siu C. Screening for emotional distress in cancer patients: a systematic review of assessment instruments. J Natl Cancer Inst. 2009:101(21):1464-88.

\section{Submit your next manuscript to BioMed Central and we will help you at every step:}

- We accept pre-submission inquiries

- Our selector tool helps you to find the most relevant journal

- We provide round the clock customer support

- Convenient online submission

- Thorough peer review

- Inclusion in PubMed and all major indexing services

- Maximum visibility for your research

Submit your manuscript at www.biomedcentral.com/submit
C) Biomed Central 